\title{
Sexual and Reproductive Health as an Indicator of Social Integration: The Obstacle of a Patriarchal Culture and Forced Marriage in Migrant Communities
}

\author{
Ornella Urpis \\ University of Trieste, Italy \\ ornella.urpis@dispes.units.it
}

Patriarchal family structure is the paradigm of human relations in many parts of the world. In these societies the relationships are structured on the rigid separation of the sexes and on the different capacity of empowerment of men and women. In migratory processes, loyalties to the traditional model of the patriarchal family often remain unchanged. Migration dynamics intertwine with the marriage strategies of families or communities, and the maintenance of certain traditional practices, including forced marriage, becomes functional to the maintaining of the boundaries of identity and to 'traditional' social system. The observation of the sexual and reproductive health of women can provide a good indicator of the integration of cultural communities because it reveals women's capacity for autonomy and self-determination, a fundamental condition for the recognition of their rights and identification with the models and values of democratic society. The access of women to health and territorial facilities, the repeated abortions, the presence of repeated sexual diseases, knowledge of family planning, knowledge of the language of the host country, the capacity for autonomy and choice on reproduction, the abandonment of behaviors of submission to traditions (endogamous marriages, forced marriages and female genital mutilation) are all indicators useful for understanding the degree of social inclusion of women and the integration of communities in the host country.

\section{Introduction}

When speaking of the integration of migrants, reference is always made to their inclusion in the labor market, their living conditions, their ability to access services, their interaction with the surrounding environment, etc. (Boccagni \& Pollini, 2012); however, equal attention is not paid to measuring the changes in their identification models or their ability to reshape the cognitive and evaluative picture in the new cultural system that now be- 
longs to them (Sayad, 2002). It is undoubtedly very difficult to assess one's ability of social adaptation and the changes gradually undergone over time by someone having the status of a migrant in a new social context. One of the fundamental yet completely neglected indicators to measure the above concerns the behavioral models between the sexes and the persistence of actions of patriarchal power (in countries where it is widespread) that restrict the life of women and negatively impact their sexual and reproductive health in particular.

Even in more advanced approaches (Bocacgni \& Pollini, 2012; Cesareo \& Blangiardo, 2009) pools of indicators are used in regards to the differing dimensions of institutional, relational, cultural, socio-temporal, socio-spatial existence; however, the relationship between the gender and the consequent to sexual and reproductive healt of women are never observed as the 'basket of integrated processes,' as defined in social science studies (Sciortino, 2015), does not include them.

The principles of personal freedom and self-determination are at the basis of the co-habitation system in every democratic host country. An individual's freedom is precondition in order for all the other constitutional freedoms to be guaranteed and it is essential so that an individual can benefit from the independence required to exercise any other right.

When it comes to women, slavery has always been associated with their bodies inasmuch as a woman's sexual and reproductive health is crucial for her self-determination and represents a fundamental indicator of her degree of independence and personal freedom.

Besides being a biological experience or a mere instinctive act, human sexuality may be viewed more broadly as a social act among individuals, having a symbolic dimension and leading to social relations and relations with the environment. Indeed, William Simon e di John H. Gagnon (Rinaldi \& Scarcelli, 2016) distance themselves from the idea of sexuality being merely a natural impulse to be held back by means of rules and rather see it from the perspective of cultural production (Rinaldi, 2016).

In this light, sexual and reproductive health becomes an indicator of integration in cultural communities, measured via women's access to: health facilities throughout the territory, legal abortion, family planning systems, learning the language of the host country, freedom of choice on reproduction, the abandonment of traditional submissive practices (endogamy, forced marriage, and female genital mutilation-FGM).

When examining only social, economic, employment, and housing factors, one might conclude that many immigrants are perfectly integrated as the 
men have jobs, their children go to school, they live in a house, etc. However, by taking a closer look at the power relations between men and women and the socio-economic integration of women, in many families the woman cannot speak the language of the host country, has no personal independence, and in particular cannot decide on her own reproductive health, is subject to her husband's or husband's family decisions in terms of contraception, number of children to be had, types of health treatment, and is sexually unhealthy.

Regarding the integration processes in society, Parsons (1971) claims that a society can be independent insofar as it can 'count' by and large on the fact that its members adequately 'contribute' to its well-functioning. In this respect, integration requires the degree of alienation of its members to be reasonably low, whereas in many communities women seem to be totally on the margins of society.

Parsons (1971) adds that the integration process of members into society is linked with a zone of inter-penetration between the social system and the personal system. It is a three-way relationship in that part of the cultural system in addition to part of the social structure are interiorized by one's personality and part of the cultural system in turn is institutionalized in society.

Unfortunately, the process of interiorization of the host country's cultural system may not be welcomed or accepted. The persistence of a patriarchal model which completely permeates the homeland's organizational structure of society and the conceptual and value-based references of many migrants prevent the natural permeation between cultural systems from happening and people from being equals (Urpis, 2017). This leads to the creation of an insurmountable barrier between men and women thus ratifying women's inferiority and estrangement from a model of open society.

\section{Loyalty to the Patriarchal Model and the diminutio of the Female Role in Society}

A patriarchal family structure is at the heart of many societies built almost exclusively on the affirmation of values. On the contrary, in more complex societies people are kept together through consensus on the procedures intended to lawfully put into effect the law and to lawfully exercise power rather than through the substantive consensus on values (Habermas, 1998).

In patriarchal societies the relationship between men and women is one based on the rigid separation of gender, on the valorization or de-valorization of differences between genders and on differing empowerment skills. Social segregation is a reflection of segregation within the family (Johnson, 1997).

Examining the persistence of patriarchal models which inevitably imply 
the discrimination of women and are fixed in traditional practices means observing how different cultures relate to each other on issues like wedding agreements, women's access to social and economic goods, discrimination and inequality.

In migratory processes loyalty to one's traditional patriarchal family model continues. Differentiated relations and the imbalance of power between genders continue, sometimes taking even more shape in the host countries and often leading to the immigrants' children also suffering the consequences as they are torn between the loyalty they owe to their family and a totally different kind of social loyalty (Lannutti, 2016). Migratory dynamics are interlinked with the marriage strategies of families and communities and the preservation of traditional practices serves as a tool for the preservation of borders of identity (Urpis, 2012).

The difficult relationship with the new society, the cultural gap, the lack of integration often lead to migrants intermingling only with members of their own cultural groups. Changes in lifestyle and customs, as well as the changes in identity which often follow, are not automatic processes at all. On the contrary, conforming with 'traditional' values and behavior become necessary conditions in order to be accepted in the host country by those who come from the same cultural milieu.

As a consequence, some foreign communities become impenetrable to the social environment around them and some practices like forced marriage and female genital mutilation, which function as differentiation elements, continue within the new cultural group of reference in order to secure the shared common values in the group.

In migratory processes an awareness of the cultural features of certain communities, in which women are particularly subject to discrimination, can help the host society choose the necessary tools to promote policies favoring social inclusion (Ambrosini \& Berti, 2009).

It is for these reasons that a crucial factor for the integration of foreigners is - in my view - the condition of female immigrants, ie their level of economic and social emancipation, their knowledge of the language spoken in the host country, their rapport with their husband/partner, their refusal to accept harmful traditional practices, their active participation in the social and political life in the new society, all of which positively impact their sexual and reproductive health.

If having a job is a condition that favors female empowerment, personal independence and the exercise of rights, one can easily doubt about immigrant women's power of self-determination and integration in Italy today. 
Data on immigrant women and the labor market show a very low level of economic integration and very widespread inactivity and unemployment on their part. As mentioned in the 5th Annual Report of the Ministry of Labor and Social Policies (Ministero del Lavoro e delle Politiche Sociali, 2015), women of extra-European origin have $10 \%$ lower employment rates compared to European women ( $46 \%$ versus $56 \%$ ) and $10 \%$ higher rates in regards to inactivity ( $43 \%$ for extra-European women and $33 \%$ for European women). The inactivity rate is up to $70 \%$ among Egyptian and Indian women and even up to $80 \%$ among those from Bangladesh and Pakistan.

This condition of emargination directly impacts their ability to interact with the new social environment they live in and to make the appropriate choices in their lives. Healthcare professionals at the hospital Burlo Garofano in Trieste complain about the language difficulties they have in communicating with certain patients from particular areas of the globe: 'We often find ourselves trying to communicate with patients who can't speak our language despite their having been in our country for several years. We need to contact cultural-linguistic mediators, but in case of an emergency we just learn to cope.' (Doctor at the Burlo Garofalo hospital). A bigger issue is the 'informed consent' procedure. Patients cannot be forced to accept a certain type of health treatment, if not by the law. Therefore, the 'informed consent' procedure allows a patient to authorize a particular type of health treatment after having been informed about it by a health professional. Unfortunately, however, patients who do not speak the local language need a translator and the cultural-linguistic mediator in charge does not always happen to be at the hospital when needed. Therefore, the woman's spouse or her relatives will intervene and often times she will leave it entirely to her husband given her condition of subordination to him: 'I have found myself in very difficult situations in which the woman would not speak and relied on her husband completely. He would decide and she would consent. On one occasion there were delivery complications and the baby showed signs of fetal distress. I had to perform a C-section but my patient would not reply. She let her husband make all the decisions and he claimed that in their culture C-sections are prohibited [...]' (Doctor at the Burlo Garofalo hospital).

As can be seen by examining the responses to the INTEGRA project questionnaire, women are almost totally dependent on their husbands. The greater their language difficulties and their inability to relate with others in the host society, the smaller their personal independence. Women from Kossovo, Bangladesh, Nigeria, Pakistan, Turkey are particularly isolated.

All of the elements above help us gain a greater understanding of how 
integration is nowhere near for those communities characterized by a patriarchal type of traditional cultural model. They also show how social policies underestimate the status of women and their sexual and reproductive health as important indicators for the measurement of a woman's degree of social inclusion in a community.

The patriarchal system, which compels women to be housewives and to have many children, prevents them from getting employment, freely interacting with the outside world and gaining personal independence. The role of a housewife is so internalized by women that even when men express the hope to find a woman who has a job and is a bit independent, the women themselves refuse to: 'I've been living here for seven years. My wife arrived after me. I always tell her to look for a job and to learn Italian, but she refuses to and is always at home. She's used to it. (Husband of a Kosovan 25-year-old woman)

In other cases, the likeliness of getting a low-level type of job instead of working at home as a housewife discourages immigrant women from job hunting altogether. The challenge of having their education qualifications earned abroad recognized lowers women's chances of ever growing socioeconomically. This seems to be the major obstacle, mentioned by foreignborn working women, in finding a job related to the education earned and the skills acquired (Centro Studi e Ricerche IDOS, 2016).

Most women who migrate to Italy today, however, come to reach their husbands. As can be seen from the data on the number of women arriving and on the number of permits to stay released, family is the key factor for women in choosing to start the migratory experience altogether.

In the past, women arrived in Italy unaccompanied to work as domestic workers, caretakers for the elderly, babysitters, which gave Italian women the freedom to look for a job. The former left their countries alone (most of them were from the Horn of Africa and later from the Philippines, the Mauritius Islands, India and Sri Lanka).

One of the major issues in the current situation is the lack of motivation to learn the Italian language or the inability to access free language courses. Language problems are the main cause for migrant women's lack of integration and they necessarily lead to difficulties with: establishing relations with society and the institutions, the lack of awareness of women's rights in Italy and of the family code, taking care of themselves and of their children.

\section{Traditions and Cultural Violence}

'Tradition' is based on cultural systems in which the patriarchal component in many societies is dominant. The institution of marriage is the most signifi- 
cant traditional practice that structures the features of communities around 'the sense of belonging,' perpetuates the sense of attachment to one's community, and more importantly maintains a social order established by men. Forced marriage, in particular, perfectly meets all the criteria for the maintenance of male power, the supervision of female sexuality, and the limitation of solidarity and cohesion among women in the light of lineage: 'Women transfer reproductive power which men have nothing to do with [...]. Such reproductive power not based on lineage leads to the solidarity with another species, almost of a mystical order, different from that determined by family relationships which are equivalent to a socially organized world of males. Nevertheless, given the ideology of patrilineal descent, women are terminologically included in the agnatic relationship, the guidelines, in which they participate and which are based on nature, disrupt the pre-established social order and continue to call it into question' (Héritier, 2004, p. 62).

The concept of forced marriage (FM) includes a series of actions aimed at the coercion of an individual (mostly women) and at binding him or her in a legal relationship without consent: 'a wedding in which one or both of the spouses does not consent (in particular, disabled adults cannot give their consensus) to the wedding and in which constraint is exercised. Constraint may include physical, psychological, financial, sexual or emotional pressure' (Serughetti, Ruggerini, Lotti, Misiti, \& Virgilio, 2014, p. 5).

The institution of marriage includes certain types of contract featuring the 'ownership of a person;' in societies based on the patriarchal model, women become the subject of economic exchange given their reproductive qualities. The concept of ownership of a person is thus the means by which relationships of subordination and devaluation of women and of their social role continue to replicate (Hamel, 2011).

Let us consider FM the series of limits imposed upon freedom in a marital relationship, for example arranged weddings, child marriage, marriage of convenience or based on interest, but also the inability to interrupt a marital relationship due to social, cultural and family pressure, and lastly the impossibility of interrupting the marital relationship (Danna, 2013).

Forced Marriage is a global issue present in large areas of the world and which takes place in migratory contexts in both traditional and new forms for the purpose of isolation from the host society. Any sort of violation of the freedom of marital choice is the violation of a fundamental human right, as established by Art. 16 of the Universal Declaration of the UN: 'Wedlock is only possible with the free and full consent of the future spouses.' Furthermore, FM is a form of violence with a clear gender profile as it mostly affects women and girls and affects their sexual freedom. 
The places where weddings are pre-arranged and the countries where such practices are still preserved feature a number of dominant cultural factors which have been identified by the Council for human rights of the United Nations (Kabasakal Arat, 2008):

- controlling female sexuality in connection with the topic of male honor,

- protecting cultural/religious traditions from modernity,

- the relationship with cultural identity, the sense of belonging and the identification with one's country of birth.

In the first case, the causes have to do with forms of cultural pressure in relation to family and male honor which result in control of female sexuality and virginity, security at an old age - given the lack of a welfare state the desire not to lose property. In many cultures the dominant principle of sexual morality links the honor of a man with the integrity of 'his woman' or of 'his women.' In order for their chastity to be guaranteed, it is essential that their sexuality and their lives be controlled very strictly. Regarding adolescents, their virginity needs to be controlled until they wed, otherwise the whole family will undergo economic and social ruin (dishonor). Let us not forget that a marriage contract informally provides for dowry which is linked directly with the virtues of a woman. Early marriage and any other imposed form of marriage is cloaked with considerations on 'the protection' of a woman and of her virtues, and minimizes precocious sexual intercourse and enhances the power of the elderly (parents and grandparents) within the family and social community. The system of authority remains unaltered and roles are clearly fixed.

The socialization of this behavior is so strong that even when a woman chooses to wed a man, she will continues to feel a sense of guilt: 'In Bangladesh women wed at the age of 16 and then begin to have children. She will not have a job, she cooks and looks after her husband. In Bangladesh everyone talks and everyone knows everything about everyone. When a young woman weds, she is at the center of all attention in the village. Everyone observes her and checks whether she is behaving the way she should. Unless you wed based on your parents' recommendations or if you are separated and you live at home with your parents you will be subject to scorn by the community. You will be the shame of the family. When I was married, I got pregnant, but then my husband left me, and my brother claimed that I could not keep a child without a husband and that if I kept my child he would abandon the family. My mother also said that if I came back home with a child but 
without a husband we would be the talk of the town. Don't you ever come back to Bangladesh. Stay in Italia. You will bring only shame here [...] and everyone will say that you are a bad woman. If I had married the man recommended by my family, perhaps things would not have ended this way, but I fell in love with him [...]' (18-year-old woman from Bangladesh)

In some cultures, elderly women and those who have a higher social status are very powerful and use every means they avail of to sexually 'educate' young women and lead them back to a condition of subordination through magic: 'By us there is a ceremony called Kpessosso which takes place in September. It is a sort of a voodoo ritual. I do not belong to that culture. It is about magic, the Vudunera. They control women. They say there is a snake that needs to be subordinated. They tell you that you need to pay the Soma otherwise you will die. And you must do what they say, so if they say you must marry a man, you must do it [...]' (A 30-year-old woman from Togo).

In the second case, it is the parents who prevent their children from becoming too European, creating their own life space, and integrating completely with the host society. In this case the spread of religious fundamentalism is also relevant. In the case examined in the Bangladesh community in Monfalcone, where the choice of a future spouse is obviously made by the parents of the families, the practice of preserving traditional costumes continues unchanged. Even after years' residing in Italy, the women do not know the Italian language, they wear traditional clothes, lead the same lifestyle they used to lead in Bangladesh, force their daughters to wear a traditional dress. Everyone knows that at the age of 18 they will wed and will have to have their first child: 'My daughter dresses like me. Our life is led among the community. I've been here for many years, almost seven. I have never had anything to do with Italian women, I do not care, it has never happened. I do only when I go shopping and when I went to the hospital, but there my husband did the talking as I am unable to speak the local language. When my daughter turns 18 , she will get married and have children. I live like I used to in the village. I go shopping, cook, speak to other women, clean, wait for my husband to get back from work. Here it is better. I have a home and we live all together. If I have problems I go to the hospital, together with my children. My children go to school. We are many here and we always stick together.' (A 31-year-old woman from Bangladesh).

The third case has to do with the identification of the country of emigration, the hope to go back one day and the emigrants' regular contact with family back home thanks to the new technologies. All of this makes the emigrant a living symbol of his nation of origin, and every disconnection with 
his traditional culture is viewed as a betrayal towards his own country and all its history.

Let us not forget that a woman's body belongs to her family and community. In politics, identification takes place by means of symbols conveyed by the female body: 'This dress belongs to my country, to my people. I must respect my culture because it is my country. One day I want to go back and be respected for not having changed who I am.' (A 27-year-old woman from Bangladesh).

The element of choice is always very problematic and many unions experience the intervention of the family in the choice of a spouse. The degree of intervention may be very high, in which case the choice is made by the family directly, or very open, in which case the candidate may express her preference among a number of candidates selected by the family.

However, 'in some cases the differences between forced marriage and prearranged marriage are merely semantic' (Thomas, 2009, p. 2); psychological pressure and other forms of manipulation are so strong and binding that they serve as a deterrent to the woman's parents' choice.

If we include in forced weddings all the forms of family or institutional violence that prevent women from ending a relationship or divorcing, then the phenomenon is much more vast and complex. No less important are the socalled 'structural constraints' (Danna, 2013), ie poverty, for example, which causes women to leave everything behind and leave with a migrant or to marry a man in order to gain citizenship in the host country and benefit from the social rights acquired through marriage.

In the INTEGRA research project by questionnaire, 77 women at the OB/GYN clinic of the hospital of Trieste were asked questions about the nature of weddings in their country of origin. When asked about freedom of choice, five women did not answer whereas 45 women claimed that 'every individual is free' (just over $60 \%$ ). The question, however, confirms that in some countries 'choice' is an issue: nine women were completely denied any choice or claimed that it was possible only on certain conditions (there is a divide between urban and rural areas) or only in certain types of family ( 16 respondents). Even though some of the interviewees claim that the situation is changing, about $35 \%$ has lived in areas of the world where forced/prearranged marriage is still current. Most of them are from Bangladesh, Pakistan, Morocco, Cameroon. The total number of Bengalese and Pakistani women admitted that forced marriage is a normal practice still today in their country.

When asked the following questions: 'Have you been promised to some- 
one? If so, to whom and at what age' most (88\%) replied that they had not been promised to anyone, but nine of those interviewed admitted that their marriage had been pre-arranged and organized by the family. Among these are Pakistani, Bengalese, Kosovan, and two African women. Of the nine women who admitted they had been promised to someone, only two named those responsible (family and parents) and one Cameroonian woman admitted she had been promised when she was only three years old.

\section{Conclusions}

'Traditions' in many cultures are based on patriarchal models that strongly influence the sexual and reproductive health, and more generally speaking the self-determination, of migrant women. In migratory processes, loyalty to one's cultural community of origin and to the system of values in one's traditional social organization does not change very easily. The role of women, which is crucial in processes of social inclusion, remains secondary. It is therefore extremely important to measure the degree of integration of a community by means of new tools including the concept of women's selfdetermination which is expressed first and foremost through the woman's ability to manage her sexuality and reproductive functions.

The INTEGRA research project shows that the interviewees are totally dependent on their husbands and live a sort of parallel life while being excluded by the host society. Family is their one and only environment for action. Integration is a mere illusion.

\section{References}

Ambrosini, M., \& Berti, F. (2009). Persone e migrazioni: integrazione locale e sentieri di co-sviluppo. Milan, Italy: Franco Angeli.

Boccagni, P., \& Pollini, G. (2012). L'integrazione nello studio delle migrazioni:Teorie, indicatori, ricerche. Milan, Italy: Franco Angeli.

Cesareo, V., \& Blangiardo, G. (Ed.). (2009). Indici di integrazione: un'indagine empirica sulla realtá migratoria italiana. Milan, Italy: Franco Angeli.

Danna, D. (2013). I confini dell'azione pubblica: matrimoni forzati e combinati. Athenea Digital, 13(2), 65-81.

Centro Studi e Ricerche IDOS. 2016. Dossier statistico immigrazione 2016. Rome: Author.

Habermas, J. (1998). Multiculturalismo: lotte per il riconoscimento. Milan, Italy: Feltrinelli.

Hamel, C. (2011). Immigrées et filles d'immigrés: le recul des mariages forces. Population \& Sociétés, No. 479. Retrieved from https://www.ined.fr/fichier/s _rubrique/19147/479.fr.pdf 
Héritier, F. (2004). Dissolvere la gerarchia. Milan, Italy: Cortina.

Johnson, A. G. (1997). The gender knot: Unraveling our patriarchallegacy. Philadelphia, PA: Temple University Press.

Kabasakal Arat, Z. F. (2008). Women's rights as human rights. The Magazine of the United Nations, 45(2/3). Retrieved from https://unchronicle.un.org/ article/womens-rights-human-rights

Lannutti, V. (2016). La formazione identitaria delle seconde generazioni. La critica sociologica, 50(198), 145-150.

Ministero del Lavoro e delle Politiche Sociali. (2015). I migranti nel mercato del lavoro in Italia. Rome, Italy: Author.

Parsons, T. (1971). The system of modern societies. Englewood Cliffs, NJ: PrenticeHall.

Rinaldi, C. (2016). Sesso, sé e societá: per una sociologia delle sessualita. Milan, Italy: Mondadori.

Rinaldi, C., \& Scarcelli, C. M. (2016). Copioni sessuali. Lecce, Italy: Kurumny.

Sayad, A. (2002). La doppia assenza: dalle illusioni dell'emigrato alle sofferenze dell'immigrato. Milan, Italy: Cortina.

Sayad, A., \& Bourdieu, P. (2004). The suffering of the immigrant. Cambridge, Italy: Polity Press.

Sciortino, G. (2015). É possibile misurare l'integrazione degli immigrati? Lo stato dell'arte (Quaderno 63). Trento, Italy: Dipartimento di Sociologia e Ricerca Sociale.

Serughetti, G., Ruggerini, M. G., Lotti, M. R., Misiti, M., \& Virgilio, M. (2014). I/ matrimonio forzato in Italia: conoscere, riflettere, proporre. Rome, Italy: Dipartimento Pari Opportunitá.

Thomas, C. (2009). Forced and early marriage: A focus on Central and Eastern Europe and Former Soviet Union Countries with selected laws from other countries. Geneve, Switzerland: United Nations Division for the Advancement of Women.

Urpis, O. (2012). Patrie, migrazioni e culture. Udine, Italy: Casamassima.

Urpis, O. (2017). Ethnicity: Some conceptual definitions. In S. Baldin \& M. Zago (Eds.), Europe of migrations: Policies, legal issues and experiences (pp. 239254). Trieste, Italy: Edizioni Università di Trieste.

S. Ličen, I. Karnjuš, \& M. Prosen (Eds.). (2019). Women, migrations

and health: Ensuring transcultural healthcare (pp. 23-34).

Koper, Slovenia: University of Primorska Press.

https://doi.org/10.26493/978-961-7055-43-6.23-34 